\title{
Tools and Symbols as Mediation: A Central Concept to Understand Ways of Improving English Acquisition and Proficiency
}

\author{
Mazlina Che Mustafa ${ }^{1,}$, Azila Alias ${ }^{1}$, Zainiah Mohamed Isa ${ }^{1}$, Mazyani Mat ${ }^{2}$, Nadiah Yan Abdullah ${ }^{2}$ \\ ${ }^{1}$ Department of Early Childhood Education, Universiti Pendidikan Sultan Idris, Malaysia \\ ${ }^{2}$ Language Centre, Universiti Pendidikan Sultan Idris, Malaysia
}

Received June 28, 2019; Revised September 5, 2019; Accepted September 12, 2019

Copyright@2019 by authors, all rights reserved. Authors agree that this article remains permanently open access under the terms of the Creative Commons Attribution License 4.0 International License

\begin{abstract}
This conceptual paper aims to illuminate a theoretical framework in which promoting ways of how second language learners may improve their English acquisition and proficiency. The theoretical framework primarily draws on a range of sociocultural perspectives, including the sociocultural positions initially defined by Lev Vygostky (1978), and theories of second language acquisition discussed by Lantolf and Thorne (2000). Tools and symbols as mediation is a central concept of sociocultural approach to second language acquisition. Three types of mediation are discussed which are mediation is a form of regulation, mediation by symbolic artifacts, and mediation through gestures.
\end{abstract}

Keywords Mediation, Sociocultural Approach, Second Language Acquisition

\section{Introduction}

Historically [1] argued that while humans sought to adapt to their external world through assimilating the laws of nature, humans also attempted to control and master their nature. The need for control led to the creation of tools [1], technical as well as mechanical [2]. Reference [1] explained:

The tool's function is to serve as the conductor of human influence on the object of activity; it is externally oriented; it must lead to changes in objects. It is a means by which human external activity is aimed at mastering and triumphing over, nature. (p. 55)

\section{The Concept of Mediation}

Vygotsky (1978) extended the notion of instrumental mediation by drawing an analogy between the role of mechanical tools and psychological tools. Psychological tools are artifacts, including mnemonic techniques, algebraic symbols, diagrams and of course language [1], [2]. Vygotsky's fundamental claim is that just as individuals use technical tools for manipulating the environment, they use psychological tools for directing and controlling their physical behaviour [1], [3]. [1] claimed that transformation of thinking processes into higher order ones is possible through the mediating function of culturally constructed artifacts including tools, symbols and more elaborate sign systems such as language. Opinions differ on the precise relation between material and mental tools [2] but [1] connected material and mental tools through their mediating function. In other words they both fall into the same psychological category. All manner of things have been considered as tools if their function or their consequence is mediation [2]. Swain, Kinnear, and Steinman (2011) noted that sociocultural theories emphasise how humans think through the creation and use of mediating tools.

Mediation is a central concept of sociocultural theories' approach to second language acquisition [5]. A fundamental principle in sociocultural theories is that human psychological processes are mediated by psychological and material tools such as the symbolic system of language [1], [6], [7], [8]. Language is the most persistent and powerful symbolic tool that humans possess to mediate their connection to the world, to each other and to themselves [9]. [10] noted that language serves as a symbolic tool to facilitate social activities, and children's appropriation of language is in and through these activities. However, children's early appropriation of language is implicit since the main function of interaction is not usually language learning but also learning other aspects, including how to participate appropriately in social activities [3]. 


\section{Mediation Is Regulation}

Mediation is a form of regulation [5], [11], [12]. Regulation can be defined as the controlling of an activity or process, usually by means of rules. [12] claimed that as children learn language, they regulate their activities linguistically. In sociocultural theories, regulation is one form of mediation referring to children's capacity to regulate their own activity through language [1]. When children acquire language, words not only function to separate specific objects and actions, they also serve to reshape biological perception into cultural perception and concepts [3].

Thinking and actions at early stages for children are at first subordinate to the words of adults (Luria \& Yudovich, 1972 cited in [3]. By subordinating their behaviour to adult speech, children acquire the particular language used by the other members and eventually utilise this language to regulate their own behaviour [3]. Subordination of the child's action and thinking to adult speech raises the child's mental and physical activity to a new and higher stage of development [1]. This enables children to acquire the particular language used by other members of a community and finally utilise this language to regulate their behaviour [3]. In other words, children develop the capacity to regulate their activity through linguistic means because this activity is initially subordinated or regulated by others. This process of developing self-regulation moves through three general stages [3].

The first stage is known as 'object-regulation' where children are often controlled by, or use objects in their environment in order to think [11], [3]. For example, when a mother asks her child to fetch a particular toy, her child does not give the toy requested by the mother as he or she is distracted by other toys or objects which are more attractive to him or her, and may thus fail to fulfil the mother's request. This is an example of the child being regulated by the other objects [3]. The second stage is termed 'other-regulation' that includes implicit and explicit mediations which involve varying levels of assistance by adults and other peers [11], [3]. This regulation is sometimes described as 'scaffolding'. The final stage is 'self-regulation' which refers to the ability to accomplish activities with minimal or no external support and can be realised through internalisation [11], [3]). Internalisation is a process of making what was once external assistance a resource that is internally available to the individual [1], [7], [13]. For example, some children may not need the assistance of objects to do addition as they are able to do it in their heads. Hence, sociocultural theories argue that learning consists of a progression from object regulation to other regulation to self-regulation, in which children go from relying on external assistance in the performance of activities to being able to perform the activities on their own [14]. In the SLA context, the same process occurs when the second language learners gain greater control over the use of their new language.

\section{Mediation by Symbolic Artifacts}

While second language learners gain greater control over the use of their new language through progressing through stages of regulation, symbolic artifacts mediate their psychological processes. Within sociocultural approach, humans use symbolic artifacts for two main reasons: firstly, as tools to mediate psychological activities and secondly, to control psychological process [12]. [11] argued that the control is voluntary, and allows humans to think about particular things, to plan, and to think rationally. In the same vein, [1] argued that humans have the ability to use symbols, not to control the environment but to mediate their own psychological activity. He suggested that while physical tools are supporting means to enhance the ability to control and change the physical world, symbolic tools serve as supporting means to control and reorganize human psychological processes. The primary tool that humans have available is language and therefore language gives the capacity to humans to go beyond the immediate environment and to think, and talk about events and objects that are far removed ([11]; [12]; [1]). In the SLA context, second language learners use language as symbolic artifacts to establish an indirect or mediated relationship between themselves and the world [3], [15], [16].

Vygotsky (1978) claimed that these are higher psychological functions because they are symbolically mediated, and ultimately come under control of the individual. [7] suggests that the process of gaining and maintaining control over complex mental processes is characterised by two features: it begins outside the individual and it is directed by language. [1] conceived of a child as learning from society some activities such as play that the society has constructed and valued. The sociocultural environment presents the child with a variety of tasks, which demand and engage the child primarily, but not exclusively, through the use of language [3]. In the early stages of development, the child is completely dependent on other people, usually the parents, who initiate the child's acting by controlling what he/she does, how he/she does and what he/she should not do [3]. For example, the parents might give an instruction to the child to sit quietly in a formal event and monitor her behaviour during the event. Parents, as representatives of the culture, and the channel through which the culture passes into the child, actualise these instructions primarily by talking to their children [3], [1].

Vygotsky (1978) argued that language separates humans from animals, making humans more efficient, and effective problem solvers. Vygotsky (1978) claimed that children, with the assistance of speech, create greater possibilities and flexibilities than animals to accomplish tasks. For example, in the process of solving a task, a child is able to 
use words to create a specific plan. The child who uses speech divides the task into two consecutive parts. Firstly, he/ she plans how to solve the problem and secondly, he/she carries out the prepared solution. This new kind of psychological structure is absent in animals, even in basic forms [1].

[1] noted that there are three stages in speech development. The first stage is called 'social speech' or 'external speech'. In this stage, a child uses speech to control the behaviour of others and to express simple thoughts and emotions such as crying and laughing [1], [9]. In infancy, speech has a mainly public function and is vital for adaptation to the social environment and learning [1]. As the child grows, speech requires a new function; it is not used solely for communication but also to assist the child to master his or her behaviour and acquire new knowledge [6], [17].

The second stage of speech development is referred to as 'egocentric speech' or 'private speech'. Piaget was the first to coin the term 'egocentric speech' in relation to the egocentric stage of child development [18]. In Piaget's view, children are not born social or able to relate to others. Instead, they are born focused solely on themselves; their desires, thoughts. It is typically the type of speech found in three to seven year-old children [9], [19]. In this stage, children often talk to themselves, regardless of whether anyone is listening to them. They think out-loud in an attempt to guide their behaviour. They may speak about what they are doing as they are doing it [9]. This type of speech has a self-regulatory function in which children process information and thought about their actions when speaking to themselves. [1] studied the egocentric speech of children engaged in various activities. Functionally, egocentric speech is the basis for inner speech while in its external form it is embedded in communicative speech [1], [19]. [1], [19] suggested that one way to increase the production of egocentric speech is to complicate a task in such a way that the child cannot make direct use of speech for its solution. When faced with such difficulty, the children's emotional language use increases as well as their efforts to achieve a more intelligent solution. As they search verbally for a new solution, their speech reveals the close connection between egocentric and socialised speech [1], [19]. [1] emphasised that egocentric speech is linked to children's social speech by many transitional forms. When children find that they are unable to solve a problem by themselves, they consult an adult and verbally describe the method that they then carry out by themselves. The children's capacity to use language as a problem-solving tool develops to socialised speech when they address the adult.

The third stage is 'inner speech'. This is the type of speech used by older children and adults [9]. [1] argued that once a child has reached this final stage, they are able to engage in all forms of higher mental functions. This stage is also called 'verbal thought stage' in which speech and thinking are connected together [9].

[20] claimed that it is difficult to explain Vygotsky's thoughts regarding how a young second language learner makes meaning, yet it is evident that Vygotsky regarded meaning making as a predictable part of a child's cultural development from external speech to internal speech. Many second language learners encounter a silent period or a silent phase [20], [21] as they go through the first stage of second language acquisition known as pre-production [22]. While Vygotsky did not discuss the silent period, there are several pieces of evidence in his writing [1], [19] that suggest the creation of thought (mother tongue thinking) may result from a transformative act of internalisation [20]. Examining the silent period through a sociocultural lens reveals that the initial stage of second language acquisition is significant [20].

In all human cultures language serves as a universal tool. Language is described as a cultural tool as it is formed and shared by all members of a specific culture. Language is also defined as a symbolic tool because each member of the culture uses language to think [6]. [1] noted that using language actively represents two distinct expressions of the social area. Firstly, psychological tools are social in the sense that they are products of the social cultural system in which individuals use these products practices. Secondly, the tools are social in the sense that they are utilised in the process of social interaction [1].

[1] studied language in two ways. The first is to make links between language and thoughts [6], [23] in which he theorised the relationship between cognitive development and language [17]. The second is to consider language as a device that serves specific social practices [6]. During the developmental process, children become active participants in their learning through the use of language and interactions with others [6], [17]. [1] claimed that children use language, in the act of speaking, as a tool for developing thought, and at the same time, they develop language through thought. This reciprocal relationship allows children to realise that the social action of using language can lead to cognitive development [17]. Interaction of thinking and speech results in experience for the learner and Vygotsky viewed this experience as an important factor in further impacting the relationship of thinking and speech [17]. Therefore, [1] claimed that language and thought are interactive dynamics and bound together.

Besides the role of language in supporting thinking, [1] perceived language as a tool for social operations. Language assists individuals to employ their social roles and the use of a language is "cultural practice with specific rules and tools in socially appropriate ways" [24], p. 300. Vygotsky [1], [19] argued that language shapes the mind to function in the most efficient way for a particular culture. Since language is both a social and cultural tool, delays in its development have consequences. Language delays impact other areas of development including motor, social 
and cognitive [6].

Vygotsky [1], [19] argued that the acquisition of language can provide a paradigm for the entire problem of the relation between learning and development. Language arises initially as a means of communication between the child and people in the child's environment. Subsequently, after language is converted to internal speech, language then organises the child's thoughts which leads to internal mental function [1], [19]. Internal speech and reflective thought arise from the interactions between the child and persons in the child's environment [1], [19]. These interactions provide the source of development of a child's voluntary behaviour [1], [19].

\section{Mediation through Gestures}

[1] regarded gestures as having an important role in the development of language. [19] further noted that intentionality develops out of gestures in conjunction with a child's word. "The word at first is a conventional substitute for the gesture: it appears long before the crucial discovery of language and before he is capable of logical operations" ([19], p. 65). This notion indicates that gestures are where the child first comes into contact in a meaningful way with semiotic (study of meaning) mediation, thus this is an essential aspect of being human [25].

One of the most insightful areas of sociocultural theories in relation to second language acquisition research deals with the appropriation and use of gestures as a form of mediation [7]. There are two general areas of interest. The first area investigates the extent to which second language learners are able to appropriate gestures that are specific to particular meaning [25], [26]. The second area studies the interface between speech and gestures as it relates to Slobin's [27] thinking for speaking hypothesis [7]. [28] claimed that there is a close connection between speech and gesture that goes beyond social communication. Gesture can contribute to the development of thinking and, as such, can function as "a separate, spatio-motoric mode of thinking” (p. 149). [29] observed that speech is at first "a conventional substitute for the gesture" (p. 98) in child development and he perceived a close connection between gesture and symbolic play.

Gesture is generally understood as manual movements that frequently occur in the absence of speech [7], [30] such as when someone waves to indicate that he or she is leaving. These types of gestures can be interpreted independently of speech [10]. According to [31], speech and gesture form a unit of thinking that he called 'growth point', a notion closely related to Vygotsky's concept of inner speech or private speech [10]. The growth point of a speech combines one verbal and one imagistic into a single meaning system [32]. It is important to note that each component of the growth point has "unique semiotic properties," each can exceed "the meaning possibilities of the other" [32], p. 144.
[1] and [32] suggested that gestures are "material carriers of thinking" (p. 155) and therefore provide "an enhanced window into mental processes" (p. 144).

[10] argued that second language speakers clearly seem to rely on gesture both to assist them access words in their second language and as a means of requesting mediation from others. [25] claimed that the appropriation of conceptual metaphors among second language learners is manifested through gestures. Concepts, according to [29], are culturally organised artifacts that play a central role in regulating one's mind. [19], [29] argued that words do not have meanings that stand independently from other words; rather word meanings are organised into networks that, taken together, and form concepts.

\section{Conclusions}

Tools and symbols are regarded as mediation. Three aspects of mediation are highlighted: mediation as regulation, mediation by symbolic artifacts, and mediation through gestures. These three aspects of mediation are important in second language acquisition because language serves as a symbolic tool to facilitate social activities and children's early appropriation of language is in and through these activities [33].

\section{Acknowledgement}

This research was fully supported by Universiti Pendidikan Sultan Idris (UPSI) under the research grant number: 2017-0332-107-01. We thank our colleagues from the Research Management and Innovation Centre, UPSI, who have provided insight and expertise that greatly assisted the research. The research project had been successfully carried out from 1 November 2017 to 31 October 2018.

\section{REFERENCES}

[1] L.S. Vygosky, Mind in the society: The development of higher psychological process. Cambridge, MA: Harvard University Press, 1978.

[2] G. McDonald, H. Le., J. Higgins, and V. Podmore, “Artifacts, tools, and classroom,” Mind, Culture, and Activity, vol. 12(2), pp. 113-127, 2009.

[3] J. P. Lantolf, and S.L. Thorne, Sociocultural theory and second language learning, In Bill B. Van Patten \& W. Jessica (Eds.), Theories in second language acquisition: An introduction (pp. 693-701), New York, NY: Routledge, 2007.

[4] M. Swain, P. Kinnear, and L. Steinman, Sociocultural theory in second language education: An introduction through 
narratives, Bristol, England: Multilingual Matters, 2011.

[5] J. P. Lantolf, Sociocultural theory and second language learning, Oxford, England: Oxford University Press, 2000.

[6] E. Bodrova, and D. Leong, (2007). Tools of the mind: The Vygotskian approach to early childhood education, Upper Saddle River, NJ: Pearson/Merrill Prentice Hall, 2007.

[7] J. P. Lantolf, Sociocultural theory and second language learning, Oxford, England: Oxford University Press, 2006.

[8] M. Swain, and P. Deters, "New mainstream SLA theory: Expanded and enriched,” in The Modern Language Journal, vol.I, 9, 2007, pp.820-836.

[9] L. Aimin, (2013). "The study of second language acquisition under socio-cultural theory", in American Journal of Educational Research, vol 1(5), p. 162-167.

[10] J. V. Wertsch, Mediation, in H. Daniels, M. Cole. \& J. V. Wertsch (Eds.) The Cambridge companion to Vygotsky (p. 178-192). New York, NY: Cambridge University Press, 2007.

[11] S. M. Gass, Second Language Acquisition: An Introductory Course (4th ed.). New York, NY: Routledge, 2013.

[12] S. M. Gass, and A. Mackey, Stimulated Recall Methodology in Second Language Research. Mahwah, NJ: Lawrence Erlbaum, 2000.

[13] S. Loewen, and H. Reinders, Key Concepts in Second Language Acquisition. New York, NY: Palgrave Macmillan, 2011.

[14] J. P. Lantolf, and S. L.Thorne, (2006). Sociocultural Theory and Second Language Learning, in B. VanPatten \& J. Williams (Eds.), Theories in Second Language Acquisition: An Introduction, (p. 201-224). Mahwah, NJ: Lawrence Erlbaum, 2006.

[15] J. P. Lantolf, and T. G Beckett, "Sociocultural theory and second language acquisition”, in Language Teaching, vol.4 (42), 459-475, 2009.

[16] J. P. Lantolf, The Sociocultural Approach to Second Language Acquisition, in Atkinson, D. (Ed.). Alternative Approaches to Second Language Acquisition. New York, NY: Routledge, 2011.

[17] J. Wink, and L. Putney, A Vision of Vygotsky. Boston, MA: Allyn \& Bacon. 2002.

[18] J. Piaget, Language and Thought of the child,University Science, 1989.

[19] L.S. Vygotsky, Thought and Language. Cambridge, MA: MIT Press, 1986.

[20] C. Bligh, The Silent Experiences of Young Bilingual Learners: A Small Scale Sociocultural Exploration. (Doctoral Dissertation). CREET: The Open University, 2011.

[21] P. O. Tabors, One Child, Two Languages: A Guide For Early Childhood Educators of Children Learning English As a Second Language, Baltimore, MD: Paul H. Brookes, 2008.

[22] S. D. Krashen, The Input Hypothesis: Issues and Implications, London, UK: Longman, 1985.
[23] A. Kozulin, Psychological Tools: A Sociocultural Approach to Education. Cambridge, MA: Harvard University Press, 1998.

[24] B. Van Oers, and M. Poland, "Schematising activities as a means for encouraging young children to think abstractly," in Mathematics Education Research Journal, vol.19, pp. 10-22, 2007.

[25] G. S McCafferty, and M. K. Ahmed, The Appropriation Of Gestures of the Abstract By L2 Learners in J. P. Lantolf (Ed.), Sociocultural Theory and Second Language Learning (pp. 199-218). Oxford, UK: Oxford University Press, 2000.

[26] G. S McCafferty, Gesture and Creating Zones of Proximal Development for Second Language Learning. The Modern Language Journal, vol. 86, 192-203, 2002.

[27] D. I. Slobin, Language and Thought Online: Cognitive Consequences of Linguistic Relativity, in D. Gentner \& S. Goldin-Meadow (Eds.), Language in mind: Advances in the study of language and thought (pp. 157-192). Cambridge, MA: MIT Press, 2003.

[28] S. G. McCafferty, Space for Cognition: Gesture and Second Language Learning. International Journal of Applied Linguistics, 14(1), 148-165, 2004.

[29] L.S. Vygotsky, The Collected Works of L.S. Vygotsky, Volume III: The Problems Of The Theory And History Of Psychology, New York, NY: Plenum, 1997.

[30] E. Negueruela, J. P Lantolf, S. R. Jordan, \& J. Gelabert, The "private function" of Gesture in Second Language Communicative Activity: A Study on Motion Verbs And Gesturing in English And Spanish. International Journal of Applied Linguistics, vol. 14, 113-147, 2004.

[31] D. McNeill, Gesture and thought. Chicago, IL: University of Chicago Press. 2005.

[32] D. McNeill, and S. Duncan, Growth Points in Thinking for Speaking, In D. Mcneill (Ed.), Language and Gesture (pp. 141-161). New York, NY: Cambridge University Press, 2000.

[33] J. V Wertsch, Mediation in H. Daniels, M. Cole. \& J. V. Wertsch (Eds.) The Cambridge Companion to Vygotsky (pp 178-192). New York, NY: Cambridge University Press, 2007. 